\title{
Lipid profile of regular blood donors
}

This article was published in the following Dove Press journal:

Journal of Blood Medicine

9 May 2013

Number of times this article has been viewed

El Uche'

A Adediran ${ }^{2}$

OD Damulak ${ }^{3}$

TA Adeyemo ${ }^{2}$

AA Akinbami ${ }^{4}$

AS Akanmu²

'Department of Hematology and Blood Transfusion, Lagos University Teaching Hospital, Lagos, Nigeria; ${ }^{2}$ Department of Hematology and Blood Transfusion, University of Lagos, Lagos, Nigeria; ${ }^{3}$ Department of Hematology and Blood Transfusion, Jos University Teaching Hospital, Jos, Nigeria; ${ }^{4}$ Department of Hematology and Blood Transfusion, Lagos State University, Ikeja, Nigeria
Correspondence: El Uche Department of Haematology and Blood Transfusion, Lagos University Teaching Hospital, Lagos, Nigeria

Tel +234 8033215159

Email eifeyinwa2000@yahoo.com
Introduction: A few reports have linked regular blood donation to the lowering of parameters of lipid profile. Estimating the lipid profile is an accepted method of assessing an individual's risk for coronary heart disease, particularly if there is evidence of lipid peroxidation. Regular blood donation may lower iron stores, and this in turn lowers lipid peroxidation. This study was carried out to determine the effect of blood donation on lipid profile.

Materials and methods: Eighty-two participants consented to participate and were enrolled into the study, 52 of whom were regular blood donors (study group) and 30 were non-donors (control group). Venous blood $(10 \mathrm{~mL})$ was drawn from each subject into new plain screwcapped disposable plastic tubes. This was allowed to clot and the serum was used to determine total cholesterol, triglycerides, low-density lipoprotein, and high-density lipoprotein.

Results: The mean total cholesterol $(4.66 \pm 0.86 \mathrm{mmol} / \mathrm{L})$, triglycerides $(1.22 \pm 0.64 \mathrm{mmol} / \mathrm{L})$, and low-density lipoprotein $(2.32 \pm 0.73 \mathrm{mmol} / \mathrm{L})$ were significantly lower in the regular blood donors than the control group $(5.61 \pm 1.26 \mathrm{mmol} / \mathrm{L}, 1.77 \pm 2.9 \mathrm{mmol} / \mathrm{L}$, and $3.06 \pm 0.89 \mathrm{mmol} / \mathrm{L}$, respectively; $P<0.05$ in all cases). Also, while $42 \%$ of the study group had a low/high-density lipoprotein ratio of at least three, about $57 \%$ of the control group had a ratio of at least three $(P=0.21)$.

Conclusion: Regular blood donation may be protective against cardiovascular disease as reflected by significantly lower mean total cholesterol and low-density lipoprotein levels in regular blood donors than in non-donors.

Keywords: donor, total cholesterol, low-density lipoprotein

\section{Introduction}

"Safe blood starts with me, blood saves lives" was the World Health Organization's theme for World Blood Donor Day Celebration on April 14, 2000. However, despite the usefulness of blood in medical practice, there is an acute shortage of blood even in large cities, with the supply below $50 \%$ of requirement. ${ }^{1}$

In Nigeria, a pilot survey of transfusion services by the Federal Ministry of Health in 2005 estimated that Nigeria collects about 500,000 units of blood annually. ${ }^{1}$ This is grossly inadequate for a country with a population of over 150 million people whose annual transfusion requirements will be (according to World Health Organization estimation criteria) about $2 \%$ of its population. ${ }^{2}$ To ensure adequacy and availability, this estimated requirement of about three million units of blood annually can be made possible if the concept of regular voluntary blood donation is imbibed in the culture. ${ }^{2}$

In most Nigerian blood banks, the majority of the donors are family replacement donors. This is because voluntary blood donation is still not well accepted by 
most people. Regular blood donation has been found to be beneficial in many ways. It challenges the bone marrow to increase its red marrow, producing more blood for the donor. It also prevents the accumulation of body iron which can cause free radical formation in the body. ${ }^{2}$

Reports that clearly state the effect of regular blood donation on the levels of serum cholesterol - a major factor in development of atherosclerosis - are very few. Does regular blood donation have a direct effect on lowering the levels of serum cholesterol through lowering of body iron stores? A study that examined the effects of blood donation found that donating blood every 6 weeks lowers the oxidation of low-density lipoprotein (LDL), which is associated with the development of atherosclerosis. ${ }^{3}$ Some studies suggest that high iron levels may play a role in this oxidation process, which is a prelude to athersclerosis..$^{3-6}$

Other studies suggest that donating blood may make blood less viscous, which could contribute to lowering the levels of LDL cholesterol and other lipids in the blood, ${ }^{7}$ perhaps due to some loss of lipids to the donated unit and dilution effect.

A lipid profile is an accepted method of assessing an individual's risk for coronary heart disease, particularly if there is evidence of lipid peroxidation. This will complement other traditional risk factors (tobacco use, age, gender, family history, hypertension, diabetes mellitus, and markers of hemostasis and inflammation such as homocysteine, fibrinogen, D-dimers, and C-reactive protein), which do not identify all patients who will experience a cardiovascular event. ${ }^{8}$

In line with this, this study aimed to assess serum lipids (which are an established nonmodifiable risk factor for cardiovascular disease) in regular blood donors and compare with those of non-donors or first-time donors.

\section{Material and methods}

The study was carried out on a total of 82 subjects, comprising 52 regular donors (study group) and 30 non-donors or first-time donors (control group). All participants were recruited from the donor clinic of the Lagos University Teaching Hospital (Lagos, Nigeria). The ethical committee of the hospital gave ethical approval for the study.

Inclusion criteria were consenting blood donors between 18-60 years of age who had donated blood at least two times in the past 12 months, four times in the past 24 months, or at least six times in the past 36 months. Exclusion criteria were donors with history of tobacco use, hypertension, diabetes mellitus, and cardiovascular disease, as well as pregnant and lactating women.

\section{Procedure}

Participants filled out questionnaires which had relevant information including age, sex, history of blood donation, hypertension, and diabetes mellitus. Venous blood (10 mL) was drawn from each participant and transferred to new plain screw-capped disposable plastic tubes and allowed to stand at room temperature until clotted and the clot retracted (about 2 hours).

After centrifugation, the serum was separated and transferred to plain cryotubes. This was aliquoted and stored at $-72^{\circ} \mathrm{C}$ until analysis was done for total cholesterol, highdensity lipoprotein (HDL), LDL, and triglycerides.

Commercial assay kits manufactured by Roche Diagnostics (Basel, Switzerland) were used to determine HDL (HDL-Cholesterol Plus 3rd Generation Kit), total cholesterol (Cholesterol CHOD-PAP Kit), LDL (LDL-Cholesterol Plus 2nd Generation Kit), and triglycerides (Triglyceride Kit). All analyses were done using the Hitachi 902 autoanalyzer (Hitachi Ltd, Tokyo, Japan).

\section{Statistical analysis}

Data was analyzed using statistical software packages: SPSS for Windows version 11.5 (SPSS Inc, Chicago, IL, USA) and Excel ${ }^{\circledR}$ (Microsoft Corporation, Redmond, WA, USA). Descriptive statistics, Chi-squared test, and Student's $t$-test were used as appropriate. The critical level of significance was set at $P<0.05$.

\section{Results}

A total of 82 subjects were enrolled into the study, 52 of whom were regular blood donors (study group) and 30 were non-donors (control group). As shown in Table 1, the subjects were aged 19-59 years. There was no significant difference in the mean age between the two groups $(35.19 \pm 7.94$ years in the study group and $33.77 \pm 9.15$ years in the control group; $P=0.461)$.

There were 34 males and 18 females in the study group, and 16 males and 14 females in the control group. There was

Table I Age distribution of subjects

\begin{tabular}{llll}
\hline Age group & Study group & Control group & Total \\
\hline$<20$ years & 0 & $\mathrm{I}$ & $\mathrm{I}$ \\
$20-29$ years & 12 & 8 & 20 \\
$30-39$ years & 24 & 13 & 37 \\
$40-49$ years & 13 & 7 & 20 \\
$\geq 50$ years & 3 & $\mathrm{I}$ & 4 \\
Total & 52 & 30 & 82 \\
Mean age, years & $35.19 \pm 7.94$ & $33.77 \pm 9.15$ & $34.70 \pm 8.4$ \\
\hline
\end{tabular}

Note: $P=0.461$. 
no significant difference between the sexes in the two groups ( $P=0.287$; Table 2).

The mean body mass index of the study group $\left(26.50 \pm 4.20 \mathrm{~kg} / \mathrm{m}^{2}\right)$ was not significantly different $(P=0.744)$ from that of the control group $\left(26.30 \pm 4.00 \mathrm{~kg} / \mathrm{m}^{2}\right)$.

The comparison of mean serum lipids in the study and control groups is presented in Table 3 . The study group had lower total cholesterol $(4.66 \pm 0.86)$, triglycerides $(1.22 \pm 0.64)$, and LDL $(2.32 \pm 0.73)$ compared with the control group $(5.61 \pm 1.26,1.77 \pm 2.91$, and $3.06 \pm 0.89$, respectively). However, only the values for total cholesterol and LDL showed a statistical difference $(P=0.000)$ in both cases. Serum HDL levels were significantly higher $(P=0.016)$ in the control group $(1.00 \pm 0.26 \mathrm{~mm} / \mathrm{L}) \mathrm{com}-$ pared with the study group $(0.86 \pm 0.24 \mathrm{~mm} / \mathrm{L})$. The LDL/ HDL ratio was lower in the study group $(2.90 \pm 1.28 \mathrm{~mm} / \mathrm{L})$ compared with the control group $(3.22 \pm 1.04 \mathrm{~mm} / \mathrm{L})$, but failed to reach significance $(P=0.247)$.

Even though there was no statistical difference in the total cholesterol, triglycerides, and LDL between the sexes in both control and study groups, the values of these parameters were lower in the study group when compared with the control group (Table 4). The mean total cholesterol, triglycerides, and LDL of females in the study group $(4.79 \pm 0.75 \mathrm{mmol} / \mathrm{L}, 1.04 \pm 0.43 \mathrm{mmol} / \mathrm{L}$, and $2.40 \pm 0.77 \mathrm{mmol} / \mathrm{L}$, respectively) was lower than that of the females in the control group $(5.24 \pm 0.98 \mathrm{mmol} / \mathrm{L}$, $2.21 \pm 4.27 \mathrm{mmol} / \mathrm{L}$, and $2.84 \pm 0.76 \mathrm{mmol} / \mathrm{L}$, respectively). Similarly, these values were also lower in the males of the study group $(4.59 \pm 0.91 \mathrm{mmol} / \mathrm{L}, 1.15 \pm 0.73 \mathrm{mmol} / \mathrm{L}$, and $2.28 \pm 0.71 \mathrm{mmol} / \mathrm{L}$, respectively) when compared with their counterparts in the control group $(5.94 \pm 1.44 \mathrm{mmol} / \mathrm{L}$, $1.39 \pm 0.47 \mathrm{mmol} / \mathrm{L}$, and $3.24 \pm 0.98 \mathrm{mmol} / \mathrm{L}$, respectively) (Table 4).

\section{Discussion}

Regular blood donors have been identified in several studies as a group with a lower risk of cardiovascular disease when compared with irregular donors or first-time donors. ${ }^{4,5}$

This study evaluated a total of 82 subjects -52 regular donors and 30 non-regular or first-time donors. This study

Table 2 Sex distribution of subjects

\begin{tabular}{llll}
\hline Sex & Study group & Control group & Total \\
\hline Males & 34 & 16 & 50 \\
Females & 18 & 14 & 32 \\
Total & 52 & 30 & 82 \\
\hline
\end{tabular}

Note: $P=0.28$.
Table 3 Comparison of mean serum lipids (mmol/L) in study $(n=52)$ and control groups $(n=30)$

\begin{tabular}{llll}
\hline Serum lipids & Study group & Control group & P-value \\
\hline Total cholesterol & $4.66 \pm 0.86$ & $5.61 \pm 1.26$ & 0.000 \\
Triglycerides & $1.22 \pm 0.64$ & $1.77 \pm 2.91$ & 0.119 \\
HDL & $0.86 \pm 0.24$ & $1.00 \pm 0.26$ & 0.016 \\
LDL & $2.32 \pm 0.73$ & $3.06 \pm 0.89$ & 0.000 \\
LDL/HDL ratio & $2.90 \pm 1.28$ & $3.22 \pm 1.04$ & 0.247 \\
\hline
\end{tabular}

Abbreviations: $\mathrm{HDL}$, high-density lipoprotein; $L D L$, low-density lipoprotein.

found a significantly lower total cholesterol $(P=0.000)$ and LDL $(P=0.000)$ in the study group compared with the control group. The triglyceride level was also lower in the study group but didn't reach significance $(P=0.119)$. Mean HDL level in the control group was significantly higher than in the study group $(P=0.016)$.

Available literature suggests that LDL/HDL values above three are associated with increased risk for cardiovascular events. ${ }^{9}$ In this regard, $57 \%$ of the control population had a ratio of three or higher compared with $42 \%$ of the study population with a ratio of three or higher, but this difference did not reach significance. The failure to reach significance might be due to the study's small sample size. A bigger study with larger sample size is required.

Panagiotakos et al in studying predictors of initial coronary heart disease, concluded that the LDL/HDL ratio is an important predictor of cardiac events. ${ }^{10}$ Similarly, Kinosian et al documented that change in LDL/HDL ratio is a better predictor of risk for coronary heart disease than individual isolated levels. ${ }^{11}$ This observation has also been corroborated by other researchers. ${ }^{12-14}$ Bharadwaj found in his study that there was a healthier lipid profile among voluntary blood donors in Chennai, and he concluded that blood donors are, as a whole, a protected group against coronary heart disease. ${ }^{4}$ Similarly, Susic and Baumer found significantly lower cholesterol, phospholipids, and esterified fatty acid levels among regular blood donors when compared with patients hospitalized and being managed for myocardial infarction. ${ }^{15}$ Meyers et al also concluded from their study that blood donation in nonsmoking men is associated with a reduced risk of cardiovascular events such as myocardial infarction, angina, and cerebrovascular accidents. This benefit was limited to current donors. ${ }^{5}$

The above findings are consistent with earlier reports and suggest that protection from cardiovascular events is conferred by regular blood donation. Further studies are needed to determine the optimal frequency of blood donation to maximally protect donors from cardiovascular events without occasioning an iron deficient state. The lower levels 
Table 4 Comparison of mean serum lipids $(\mathrm{mmol} / \mathrm{L})$ in study and control groups segregated according to sex

\begin{tabular}{|c|c|c|c|c|c|c|c|c|c|c|}
\hline \multirow[t]{2}{*}{ Serum lipids } & \multicolumn{3}{|c|}{ Study group } & \multicolumn{3}{|c|}{ Control group } & \multicolumn{4}{|c|}{$P$-value } \\
\hline & $\begin{array}{l}\text { Females } \\
n=18\end{array}$ & $\begin{array}{l}\text { Males } \\
n=34\end{array}$ & $\begin{array}{l}\text { Total } \\
n=52\end{array}$ & $\begin{array}{l}\text { Females } \\
n=14\end{array}$ & $\begin{array}{l}\text { Males } \\
n=16\end{array}$ & $\begin{array}{l}\text { Total } \\
n=30\end{array}$ & $*$ & $* *$ & $* * *$ & $* * * * *$ \\
\hline Total cholesterol & $4.79 \pm 0.75$ & $4.59 \pm 0.91$ & $4.66 \pm 0.86$ & $5.24 \pm 0.98$ & $5.94 \pm|.4|$ & $5.61 \pm 1.26$ & 0.400 & 0.822 & 0.165 & 0.160 \\
\hline Triglycerides & $1.04 \pm 0.43$ & $1.15 \pm 0.73$ & $1.11 \pm 0.64$ & $2.21 \pm 4.27$ & $1.39 \pm 0.47$ & $1.77 \pm 2.91$ & 0.498 & 0.481 & 0.315 & 0.169 \\
\hline $\mathrm{HDL}$ & $0.89 \pm 0.22$ & $0.84 \pm 0.25$ & $0.86 \pm 0.24$ & $0.99 \pm 0.28$ & $1.00 \pm 0.26$ & $1.00 \pm 0.26$ & 0.464 & 0.921 & 0.291 & 0.045 \\
\hline LDL & $2.40 \pm 0.77$ & $2.28 \pm 0.71$ & $2.32 \pm 0.73$ & $2.84 \pm 0.76$ & $3.24 \pm 0.98$ & $3.06 \pm 0.89$ & 0.585 & 0.219 & 0.117 & 0.000 \\
\hline
\end{tabular}

Notes: *Comparing females and males in the study group; **comparing females and males in the control group; ***comparing females in the study group with females in the control group; *****comparing males in the study group with males in the control group.

Abbreviations: HDL, high-density lipoprotein; LDL, low-density lipoprotein.

of serum lipids and the beneficial effects should form part of prospective blood donor information in Nigeria.

\section{Conclusion}

Markers of increased cardiovascular risk appear to be lower in regular blood donors compared with non-donors as reflected by significantly lower total cholesterol and LDL levels. Although HDL appears to be significantly higher in the nondonor population, the LDL/HDL ratio - which is a better predictor of increased cardiovascular risk - is lower in regular blood donors. It thus appears that regular blood donation is associated with lowering of serum lipids. However, a larger study needs to be carried out to confirm these findings.

\section{Disclosure}

The authors report no conflicts of interest in this work.

\section{References}

1. National Blood Transfusion Services. Nigerian National Blood Policy: Revised November 2005. Abuja: Federal Ministry of Health; 2006. Available from: http://www.fmh.gov.ng./images/PolicyDoc/FMOH_ Nigerian_National_Blood_Policy.pdf. Accessed December 22, 2009.

2. World Health Organization. Management of blood transfusion services [webpage on the Internet]. Geneva: World Health Organization; 1990. Available from: www.who.int/iris/handle/10665/39295. Accessed November 22, 2009.

3. van Jaarsveld H, Pool GF. Beneficial effects of blood donation on high density lipoprotein concentration and the oxidative potential of low density lipoprotein. Atherosclerosis. 2002;161(2):395-402.
4. Bharadwaj RS. A study of lipid profiles among male voluntary blood donors in Chennai city. Indian J Community Med. 2005;30(1):16-17.

5. Meyers DG, Strickland D, Maloley PA, Seburg JK, Wilson JE, McManus BF. Possible association of a reduction in cardiovascular events with blood donation. Heart. 1997;78(2):188-193.

6. Sloop GD. Possible association of a reduction in cardiovascular events with blood donation. Heart. 1998;79(4):422.

7. About.com. Cholesterol: medications and treatments [webpage on the Internet]. New York, NY: About Group; 2009. Available from: http://cholesterol.about.com/od/treatments/a/blooddonation. Accessed April 9, 2013.

8. Henriksen T, Mahoney EM, Steinberg D. Enhanced macrophage degradation of biologically modified low density lipoprotein. Arteriosclerosis. 1983;3(2):149-159.

9. Wiklund O. Treating lipids in cardiovascular disease: new directions. Eur Heart J Suppl. 2001;13(Suppl B):B27-B31.

10. Panagiotakos DB, Pitsavos C, Skoumas J, et al. Importance of LDL/ HDL cholesterol ratio as a predictor for coronary events in patients with heterozygous familial hypercholesterolaemia: a 15-year follow-up (1987-2002). Curr Med Res Opin. 2003;19(2):89-94.

11. Kinosian B, Glick H, Preiss L, Puder KL. Cholesterol and coronary heart disease: predicting risk in men by changes in levels and ratios. J Investig Med. 1995;43(5):443-450.

12. Kimura T, Itoh T, Fusazaki T, et al. LDL/HDL ratios predicts lipid-rich coronary plaque in patients with coronary artery disease - integrated backscatter intravascular ultrasound study. Circ J. 2010;74(7): 1392-1398.

13. Wilson PW, D'Augusto RB, Levy D, Belanger AM, Silbershatz H, Kannel WB. Prediction of coronary heart disease using risk factor categories. Circulation. 1998;97(18):1837-1847.

14. Hadaegh H, Harati H, Ghanbarian A, Azizi F. Prevalence of coronary heart disease among Tehran adults: Tehran Lipid and Glucose Study. East Mediterr Health J. 2009;15(1):157-166.

15. Susic D, Baumer A. [Serum lipids and uric acid values in 117 occasional blood donors and 16 post-infarction patients.] Klin Wochenschr. 1970;48(14):847-852. German.
Journal of Blood Medicine

\section{Publish your work in this journal}

The Journal of Blood Medicine is an international, peer-reviewed, open access, online journal publishing laboratory, experimental and clinical aspects of all topics pertaining to blood based medicine including but not limited to: Transfusion Medicine; Blood collection, Donor issues, Transmittable diseases, and Blood banking logistics; Immunohematology; Artificial and alternative

\section{Dovepress}

blood based therapeutics; Hematology; Biotechnology/nanotechnology of blood related medicine; Legal aspects of blood medicine; Historical perspectives. The manuscript management system is completely online and includes a very quick and fair peer-review system. Visit http://www.dovepress.com/ testimonials.php to read real quotes from published authors. 